\title{
Development of screening criteria for microplastic particles in air and atmospheric deposition: critical review and applicability towards assessing human exposure
}

\author{
Stephanie L. Wright ${ }^{1}$, Todd Gouin ${ }^{2 *}$, Albert A. Koelmans ${ }^{3}$ and Lisa Scheuermann ${ }^{4}$
}

\begin{abstract}
Over the last several years there has been an increase in studies reporting the presence of microplastic particles (MPs) in both indoor and outdoor air. Data reported reflect a variety of different types of air samples, which have helped to demonstrate the ubiquity of MPs in the atmosphere and their potential contribution to atmospheric particulate matter (PM). The relative quality of the data reporting on MPs in air has not been evaluated, but represents an important step towards improving our overall understanding of the human health implications in relation to inhalation exposure to MPs. Adopting recent approaches that have been proposed to assess the quality of data for those studies reporting concentrations in biota and water samples, we identify a suite of criteria used to screen studies reporting MPs in air for the purposes of evaluating their usefulness in assessing human exposure. Here we review and summarize data from 27 studies reporting MPs in various types of air samples and evaluate each of the studies against 11 separate criteria representing four main categories (sampling; contamination mitigation; sample purification / handling; characterization and application towards assessing human exposure). On average, studies scored $48.6 \%$ (range $18.2-81.8 \%$ ) of the maximum score. Only one study received a positive score for all criteria, implying that there remains a need for future studies to consider strengthening implementation and reporting of QA/QC protocol. The most urgent areas requiring attention relate to the need for studies to avoid and verify background contamination and to strengthen the quantification of method recovery efficiencies. The majority of studies report data for particulates $>10 \mu \mathrm{m}$. Due to the associations between exposure to particles $<10 \mu \mathrm{m}$ and human health effects, we recommend that prioritization efforts that develop standard protocols, based on existing air sampling methods capable of characterizing MPs $<10 \mu \mathrm{m}$ are progressed.
\end{abstract}

Keywords: Microplastic, Atmosphere, Review, Analytical, Monitoring

\section{Introduction}

Microplastic pollution refers to the environmental presence of plastic particles and fibres that are $\leq 5 \mathrm{~mm}[1,2]$. Microplastic particles (MPs) can be released throughout the production, use and disposal of plastic articles and

\footnotetext{
*Correspondence: todd.gouin@environresearch.com

${ }^{2}$ TG Environmental Research, Sharnbrook, Bedfordshire, UK

Full list of author information is available at the end of the article
}

synthetic textiles, for example, via photo and chemical degradation and/or abrasion and fragmentation [3-9]. Growing knowledge of the contamination of drinking water, dust and food by MPs has raised concern for human exposure and potential subsequent impacts on public health $[2,10,11]$. Robust data, characterizing and quantifying the exposure associated with both inhalation and oral exposure pathways, however, are limited, a key
Springer Open

(c) The Author(s). 2021 Open Access This article is licensed under a Creative Commons Attribution 4.0 International License, which permits use, sharing, adaptation, distribution and reproduction in any medium or format, as long as you give appropriate credit to the original author(s) and the source, provide a link to the Creative Commons licence, and indicate if changes were made. The images or other third party material in this article are included in the article's Creative Commons licence, unless indicated otherwise in a credit line to the material. If material is not included in the article's Creative Commons licence and your intended use is not permitted by statutory regulation or exceeds the permitted use, you will need to obtain permission directly from the copyright holder. To view a copy of this licence, visit http://creativecommons.org/licenses/by/4.0/. 
factor that strongly influences the ability to assess the implications for human health and to perform an assessment of risk [2, 11, 12].

Throughout the development of the research field, a major challenge towards the acquisition of high quality data on microplastic occurrence are observations reporting false positives that have been attributed to background air contamination, evidenced by the presence of MPs in procedural blanks $[5,13]$. The presence of MPs in outdoor air is further supported by studies reporting on their presence in atmospheric deposition and dust samples collected from urban, rural and remote locations [3-6, 9, 14-24]. Observations reported in these studies demonstrate the ubiquity of MPs and their contribution to atmospheric particulate matter (PM), which represents a complex mixture of particulates from varying sources, both natural and anthropogenic [25].

It is well understood that exposure to PM represents a potential human health risk [26]. For human inhalation exposure - particles having an aerodynamic diameter < $10 \mu \mathrm{m}$ (PM10) and $\leq 2.5 \mu \mathrm{m}$ (PM2.5) represent the greatest respiratory and cardiovascular hazard $[25,26]$ and is therefore a fundamental property to characterize and quantify in respect to human health implications. Airborne PM, with aerodynamic diameters (D) $\leq 100 \mu \mathrm{m}$, represents an inhalable fraction, with particles $\geq 10 \mu \mathrm{m}$ being deposited in the nasopharyngeal airway [27, 28]. For PM with $\mathrm{D} \leq 10 \mu \mathrm{m}$ there is an increased potential to reach and deposit in the intrathoracic regions of the respiratory system and PM with $\mathrm{D} \leq 2.5 \mu \mathrm{m}$ have the potential to reach the alveolar regions of the lung [25]. For instance, it has been shown that approximately $100 \%$ of particles with $\mathrm{D} \geq 10 \mu \mathrm{m}$ deposit in the nasopharyngeal region of the respiratory tract when breathing through the nose and that approximately $40 \%$ of PM with $\mathrm{D} \geq$ $10 \mu \mathrm{m}$ depositing in the lower respiratory tract of the thorax when breathing completely through the mouth [29]. Inhalation is affected by the particle properties, concentration and duration of exposure, and by age, gender, presence of respiratory diseases and possibly obesity [30-33]. Characterizing and quantifying the concentrations of PM relative to D thus represents an important source of information needed to assess human inhalation exposure.

The relative quality of the data reporting on MPs in air has not currently been evaluated. However, as discussed above, the concentrations of MPs in air, particularly those with a human health-relevant aerodynamic particle size (i.e. $\leq 10 \mu \mathrm{m}$ ), represents an important factor in helping to assess human exposure and risk as well as future research initiatives and/or the decision-making process with respect to MPs. Recently, Koelmans et al. [34] conducted a critical review and quality assessment of several studies reporting on MPs in fresh- and drinking water. An important contribution of the review is the development of guidance proposed towards the application of best practices with respect to assessing the concentrations of MPs in drinking water. The guidance and quality assessment are articulated using a scoring system, whereby studies are evaluated based on how they addressed several fundamental quality assessment and quality control (QA/QC) practices, sample method development, extraction, clean-up and analytical verification and data reporting. Nine separate criteria are evaluated, with each criterion quantitatively assessed based on a score of ' 0 ', ' 1 ' or ' 2 ', depending on how well the criterion is addressed in the study. Similar analytical challenges can be defined between characterizing and quantifying MPs in drinking water and in air. As with the analysis of MPs in drinking water, for instance, the absence of readily available standard methods applying robust QA/QC best practices and adequate reporting, represents a limiting factor towards estimating exposure. The need to address current data gaps with respect to the presence of MPs in air coupled with the lack of standard methods can therefore result in the application of modified and/or ad hoc sampling protocols using a variety of analytical methods. Given the relatively recent and rapid progress towards characterizing and quantifying MPs in air, efforts to evaluate initial progress and provide guidance towards future research is important in helping to strengthen the human exposure assessment.

The aim of this study is to review the available literature on MPs in air and atmospheric deposition using a suite of screening criteria. To achieve this, a review of the literature with respect to the concentration, polymer type, shape and size distribution across all studies reporting MPs in air is conducted. Interpretation of how studies are evaluated against the screening criteria enable recommendations for guidance towards best practices for improving the quality of future environmental studies on MPs in air for human exposure and health impact assessment.

\section{Methods}

\section{Literature review}

A literature search using both Scopus and the PubMed search engine, provided by the National Center for Biotechnology Information, and the search term 'microplastic' AND ('air' OR 'airborne' OR 'atmosphere' OR 'ambient')' was used. No restrictions on document type were applied. Only peer-reviewed papers reporting primary concentration data up to June 2020 were included for assessment.

\section{Sample type definitions}

The papers were categorised by sample type defined as the following: 
'Deposition' - refers to samples consisting of atmospheric particle fallout (includes wet and dry deposition), collected over a known surface area and time, thereby generating a rate of deposition or loading. These types of samples indicate what is present in the environment. They may indicate re-suspension or, for elevated sampling sites, capacity for vertical distribution, atmospheric transport and wider dispersion. In indoor settings, these samples may indicate what one is exposed to via ingestion, such as during a meal [35]. Additionally, studies reporting on microplastic in snow and moss have been included as these studies specifically refer to the data collected and reported as representing surrogates for evaluating atmospheric deposition.

'Dust' - refers to samples consisting of retrospectively collected ground or surface deposits, e.g. via sweeping. These samples give an indication of levels present and exposure via passive ingestion could be estimated.

'Ambient air' - refers to samples of suspended particulates collected by actively pumping air proximal to where exposure would occur, e.g., ground level and/ or at average adult breathing height. These samples give an indication of inhalation exposure, with emphasis on particle sizes relevant to the anatomical site of deposition being dependent on $\mathrm{D}$.

'Atmospheric air' - refers to samples of suspended particulates collected by actively pumping air at a height, e.g. on a roof top. These samples give an indication of background levels, vertical distribution and potential for wider environmental transport.

\section{Screening assessment scoring}

The evaluation of the data reported in the retrieved studies were screened against criteria originally developed for MPs in biota samples [36], and which was adapted for evaluating studies reporting MPs in drinking water by Koelmans et al. [34] and MP ecotoxicological effects studies [37]. A more qualitative evaluation of studies aimed at studying the relative importance of the role that MPs play as vectors of chemical contaminants has also been recently completed [38]. The valuable insight and guidance that has been obtained through the various applications of the approach originally described by Hermsen et al., [36] implies that adopting the approach to evaluate studies reporting MPs in air represents an intuitive and reasonable next step. Therefore, the criteria and general approach have been modified accordingly towards an evaluation of studies reporting MPs in air and atmospheric deposition and are further supported by recommendations recently reported by both Brander et al. [39] and Cowger et al. [40, 41]. Each of the studies identified through the literature review have been scored by at least two of the authors across
11 criteria. For each criterion, a value of 2 (reliable), 1 (reliable to a limited extent) or 0 (unreliable) is assigned. The final score is expressed as a total assessment score (TAS) calculated as the sum of each of the individual scores to give a maximum value of 22. Following Hermsen et al. [36] and Koelmans et al. [34], a reliable study should not have 'zero' scores for any individual criterion, implying that all criteria are equally important. Table 1 summarizes each of the individual criteria.

\section{Results}

\section{Literature review}

A total of 27 studies were identified from the literature review. The literture review was performed until June 2020 and only those studies reporting original concentration data were reviewed. Nine of the studies measure bulk deposition (wet and dry), nine report concentrations in air, six report MPs in dust samples, with one study reporting on MPs in snow and another on moss. In addition, three studies include indoor air samples.

\section{Quality assessment scores}

Table 2 summarizes the individual scores for each of the studies. The average TAS across all studies is 10.3, with scores ranging between 2 and 18 (Table 2). A detailed summary of the scoring evaluations are provided in the Supplementary Information. All but one study received a score of either ' 1 ' or ' 2 ' in relation to how the sample method was reported, with an average score of 1.5 (Fig. 1), causing this criterion to be reported in a consistent and satisfactory manner across all studies. Two studies included the use of positive controls with all other studies receiving a score of ' 0 ' for this criterion. The limited application of positive controls is identified as the criterion receiving the lowest average score across all studies (Fig. 1). Only one study received no non-zero scores across all criteria.

\section{Sample methods}

Sampling methods employed in the evaluated studies were assessed to ensure adequate details were included as per the criteria for each sample type. Deposition samples have commonly been collected via a simple funnelbottle construction, whereby a user periodically rinses the funnel surface and collects the bottle contents. Glass bottles and stainless-steel funnels are typically used. Routine rainfall sampling equipment [20] and assemblies for bulk deposition collection [20, 22] have also been used. One study used open glass bottles only [15]. This collection method results in a small surface area being sampled, causing extrapolation to the larger geographic area (e.g., $\mathrm{m}^{2}$ ) to be accompanied with a higher level of uncertainty. Optimizing sample surface area is therefore an important consideration when deriving geographically 
Table 1 The criteria to be met to achieve corresponding scores. The criteria are considered met if they are inferred in a publication

\begin{tabular}{|c|c|c|c|}
\hline & & & Scores \\
\hline & & & 2 \\
\hline Sampling & 1 & $\begin{array}{l}\text { Sampling } \\
\text { methods }\end{array}$ & $\begin{array}{l}\text { Dust: } \\
\text { - Location } \\
\text { - Date } \\
\text { - Apparatus } \\
\text { - Mass/area collected } \\
\text { Atmospheric deposition: } \\
\text { - Sampler description (incl. } \\
\text { Collection surface area) and } \\
\text { whether bulk or wet deposition } \\
\text { collected } \\
\text { - Location } \\
\text { - Date } \\
\text { - Height (of sampler and site, if } \\
\text { appropriate) } \\
\text { - Sampling duration (per sample } \\
\text { and per campaign) } \\
\text { - Materials used (e.g. filtered water } \\
\text { in sample collection) } \\
\text { Suspended particulates (air): } \\
\text { - Location } \\
\text { - Sampling instrument (make, } \\
\text { model) } \\
\text { - Aerodynamic size fraction } \\
\text { - Flow rate } \\
\text { - Height (of sampler and site for } \\
\text { atmospheric air) } \\
\text { - Filter substrate } \\
\text { - Sampling duration (per sample } \\
\text { and campaign) } \\
\text { - Date and meteorological } \\
\text { conditions }\end{array}$ \\
\hline
\end{tabular}

2 Sampling duration

\section{Sample processing and storage}

Contamination mitigation

4 Laboratory preparation

\section{1}

The study reports only a subset of the required criteria (e.g., date, location, materials used), however is still reproducible.

\section{0}

Insufficient reporting of sampling methods.
Atmospheric deposition: typically coarse resolution (e.g. 1 week or 1 month)

Suspended particles (air): 24-72 $\mathrm{h}^{*}$ for low volume $(16.7 \mathrm{~L} / \mathrm{min})$ sampler

Sample duration may be shorter, depending on nature of sample (e.g. if highly polluted, high organic content etc), whether a high or low volume sampler is used and research question (e.g. if interested in a specific activity). *72 $\mathrm{h}$ defined as optimum by Liu et al., 2019a, whilst 24h typical for PM10 sample collection (EN 12341).

Atmospheric deposition: Sample collection using filtered water.

Store sample shortly after collection in the dark at $4{ }^{\circ} \mathrm{C}$ or filter, dry and store in cool, dark place.

Suspended particles (air):

Transfer filter to a petri dish. Store in cool, dark place.
- Cotton lab coat or non-synthetic clothes

- Equipment and lab surfaces wiped and rinsed

- Plastic avoided in the protocol where appropriate

- All apparatus used is rigorously cleaned with ultrapure water and/
Application of consistent sampling Inconsistent sampling resolution to the best of the authors ability, which is appropriate to address the research question. durations unrelated to research question or sample type, or insufficient reporting.
Insufficient storage at room temperature and/or or storage. Unnecessary exposure or contamination risk during transportation.
Criteria only partially met, e.g., solely wiping laboratory surfaces and equipment, not wearing a cotton lab coat.
No precautions or insufficient reporting. 
Table 1 The criteria to be met to achieve corresponding scores. The criteria are considered met if they are inferred in a publication (Continued)

\begin{tabular}{|c|c|c|c|c|c|}
\hline & & & \multicolumn{3}{|l|}{ Scores } \\
\hline & & & 2 & 1 & 0 \\
\hline & & & $\begin{array}{l}\text { or filtered solvents } \\
\text { - All reagents and solvents used } \\
\text { are filtered }\end{array}$ & & \\
\hline & 5 & $\begin{array}{l}\text { Clean air } \\
\text { conditions }\end{array}$ & $\begin{array}{l}\text { - Clean room or laminar flow } \\
\text { cabinet } \\
\text { - The use of a clean room should } \\
\text { be classified in accordance with } \\
\text { ISO } 14644 \text { and/or providing an } \\
\text { indication of the maximum } \\
\text { permitted airborne particle } \\
\text { concentration. }\end{array}$ & $\begin{array}{l}\text { Mitigation of airborne } \\
\text { contamination by carefully keeping } \\
\text { samples closed as much as } \\
\text { possible IF negative samples were } \\
\text { run in parallel and examined for } \\
\text { occurring contamination. }\end{array}$ & $\begin{array}{l}\text { No regard for airborne } \\
\text { contamination, sole use of } \\
\text { normal fume hood, or } \\
\text { insufficient reporting. }\end{array}$ \\
\hline & 6 & $\begin{array}{l}\text { Negative control } \\
\text { (blanks) }\end{array}$ & $\begin{array}{l}\text { 1) Field controls collected either in } \\
\text { parallel to samples (paired) or } \\
\text { throughout the sampling period } \\
\text { (at least in triplicate), but without } \\
\text { exposure to air/deposition. } \\
\text { 2) Laboratory (procedural) controls } \\
\text { (at least in triplicate) treated and } \\
\text { analysed in parallel to actual } \\
\text { samples. } \\
\text { Sample concentrations need to be } \\
\text { reported accounting for controls, } \\
\text { i.e. deducting the baseline by } \\
\text { microplastic count, shape and } \\
\text { polymer type. }\end{array}$ & $\begin{array}{l}\text { Insufficient form of a control, e.g. } \\
<3 \text { replicates, reporting of } \\
\text { negative control results but no } \\
\text { indication of whether sample data } \\
\text { have been blank corrected. }\end{array}$ & $\begin{array}{l}\text { No negative controls or } \\
\text { insufficient reporting. }\end{array}$ \\
\hline \multirow[t]{2}{*}{$\begin{array}{l}\text { Sample } \\
\text { purification/ } \\
\text { handling }\end{array}$} & 7 & Positive control & $\begin{array}{l}\text { Controls (at least in triplicate) with } \\
\text { an added amount of microplastic } \\
\text { particles treated alongside the } \\
\text { samples, and for which the particle } \\
\text { recovery rates are determined. }\end{array}$ & $\begin{array}{l}\text { Insufficient form of a positive } \\
\text { control (e.g. if only a part of the } \\
\text { protocol is tested). }\end{array}$ & $\begin{array}{l}\text { No positive controls or } \\
\text { insufficient reporting. }\end{array}$ \\
\hline & 8 & $\begin{array}{l}\text { Sample treatment } \\
\text { (if necessary - } \\
\text { where not } \\
\text { necessary a score } \\
\text { of } 2 \text { is assigned) }\end{array}$ & $\begin{array}{l}\text { Dust only: } \\
\text { Sieving } \\
\text { All sample types: } \\
\text { Digestion of sample using a } \\
\text { protocol such as wet peroxide } \\
\text { oxidation (WPO) and/or enzymes. If } \\
\text { another chemical was used, effects } \\
\text { on different polymers should be } \\
\text { tested before application and } \\
\text { reported. } \\
\text { All sample treatments need to be } \\
\text { carried out below } 50^{\circ} \mathrm{C} \text { to prevent } \\
\text { any damage to microplastics or } \\
\text { changes in glass transition } \\
\text { temperature. }\end{array}$ & $\begin{array}{l}\text { If WPO is carried out without } \\
\text { cooling or digestion temperature } \\
\text { exceeds } 50^{\circ} \mathrm{C} \text {. }\end{array}$ & $\begin{array}{l}\text { If proof is missing that } \\
\text { polymers are not affected } \\
\text { by the protocol (e.g. } \\
\left.\text { heated } \mathrm{KOH}>50^{\circ} \mathrm{C}\right) / \\
\text { insufficient reporting. }\end{array}$ \\
\hline \multirow[t]{2}{*}{$\begin{array}{l}\text { Microplastic } \\
\text { characterisation } \\
\text { and application } \\
\text { towards assessing } \\
\text { human exposure }\end{array}$} & 9 & $\begin{array}{l}\text { Filter/substrate } \\
\text { composition }\end{array}$ & $\begin{array}{l}\text { Appropriate for the subsequent } \\
\text { analysis i.e. inert, flat/membrane. }\end{array}$ & $\begin{array}{l}\text { Quartz fibre filters (when analysing } \\
\text { directly via micro-spectroscopy) } \\
\text { OR composition which interferes } \\
\text { with analysis }\end{array}$ & Insufficient reporting. \\
\hline & 10 & $\begin{array}{l}\text { Polymer } \\
\text { identification }\end{array}$ & $\begin{array}{l}\text { Automated, semi-automated OR } \\
\text { rigorous operator-based approach: } \\
\text { Detailed and repeatable method } \\
\text { incl. Whether MP analysed directly } \\
\text { in sample or transferred to new } \\
\text { substrate, spread of particles } \\
\text { analysed across samples OR per } \\
\text { filter } \geq 25 \% \text { of the surface area } \\
\text { analysed. High percent of } \\
\text { suspected MPs analysed, i.e. } \\
\text { analysis of all particles for when } \\
\text { numbers of pre-sorted particles are } \\
<100 \text { or at least } 50 \% \text { when particle }\end{array}$ & $\begin{array}{l}\text { Hit quality indices }<70 \% \text { when } \\
\text { library matching; low percent of } \\
\text { suspected MP/sample area } \\
\text { analysed; no indication of whether } \\
\text { analysed microplastics are evenly } \\
\text { distributed across samples; no } \\
\text { indication of whether microplastic } \\
\text { were analysed directly in a sample } \\
\text { or manually transferred. } \\
\text { Identification with SEM/EDX to } \\
\text { distinguish polymer vs non- } \\
\text { polymeric materials. }\end{array}$ & $\begin{array}{l}\text { No polymer identification } \\
\text { performed or insufficient } \\
\text { reporting. }\end{array}$ \\
\hline
\end{tabular}


Table 1 The criteria to be met to achieve corresponding scores. The criteria are considered met if they are inferred in a publication (Continued)

\section{Scores}

\section{2}

numbers > 100; high HQls ac-

cepted (> 70\%);

Details of library/database included

OR details of software/programme.

11 Particle characterisation for human exposure
Detailed reporting including maximum/minimum particle size, and particle size limit of detection. Length and diameter of fibres reported.

Classified as fibres if aspect ratio >

3:1.
No mention of minimum size/ Insufficient reporting.

limits of detection.

Sizes based on suspected

microplastic (not confirmed microplastic).

Table 2 An overview of individual and accumulated scores for evaluation criteria from studies reporting microplastic concentrations in air, atmospheric deposition, snow, dust and moss

\begin{tabular}{|c|c|c|c|c|c|c|c|c|c|c|c|c|c|}
\hline \multirow[t]{2}{*}{ Source } & \multirow[t]{2}{*}{ Sample type } & \multicolumn{11}{|c|}{ Evaluation Criteria $^{a}$} & \multirow[t]{2}{*}{ TAS } \\
\hline & & 1 & 2 & 3 & 4 & 5 & 6 & 7 & 8 & 9 & 10 & 11 & \\
\hline Wright et al. (2020) [42] & Deposition & 2 & 2 & 2 & 2 & 1 & 1 & 1 & 2 & 2 & 1 & 2 & 18 \\
\hline Gaston et al. (2020) [43] & Air (outdoor and indoor) & 2 & 2 & 0 & 2 & 0 & 2 & 0 & 2 & 1 & 2 & 2 & 15 \\
\hline Wang et al. (2020) [44] & Air (outdoor) & 2 & 2 & 1 & 2 & 1 & 1 & 0 & 2 & 1 & 2 & 1 & 15 \\
\hline Klein and Fischer (2019) [22] & Deposition & 2 & 2 & 1 & 2 & 1 & 2 & 0 & 1 & 2 & 1 & 1 & 15 \\
\hline Bergmann et al. (2019) [3] & Snow & 1 & 0 & 1 & 2 & 2 & 1 & 0 & 2 & 2 & 2 & 2 & 15 \\
\hline Vianello et al. (2019) [45] & Ambient Air (indoor) & 2 & 2 & 0 & 1 & 2 & 1 & 0 & 2 & 2 & 1 & 1 & 14 \\
\hline Liu et al. (2019) [46] & Air (outdoor) & 1 & 2 & 1 & 2 & 2 & 0 & 0 & 2 & 1 & 1 & 1 & 13 \\
\hline Stanton et al. (2019) [47] & Deposition & 1 & 2 & 1 & 2 & 1 & 1 & 0 & 2 & 2 & 0 & 1 & 13 \\
\hline Allen et al. (2019) [20] & Deposition & 2 & 1 & 2 & 0 & 1 & 1 & 0 & 1 & 2 & 1 & 1 & 12 \\
\hline Liu et al. (2019) [48] & Air (outdoor) & 2 & 1 & 1 & 2 & 2 & 0 & 0 & 0 & 1 & 1 & 1 & 11 \\
\hline Dris et al. (2016) [5] & Deposition & 2 & 1 & 1 & 1 & 0 & 1 & 0 & 2 & 1 & 1 & 1 & 11 \\
\hline Zhang et al. (2019) [24] & Dust & 1 & 0 & 1 & 0 & 0 & 1 & 2 & 2 & 2 & 2 & 0 & 11 \\
\hline Roblin and Aherne (2020) [49] & Moss & 2 & 0 & 0 & 2 & 2 & 2 & 0 & 1 & 1 & 0 & 1 & 11 \\
\hline Brahney et al. (2020) [21] & Deposition & 1 & 1 & 1 & 0 & 0 & 2 & 0 & 2 & 1 & 1 & 2 & 11 \\
\hline Li et al. (2020) [50] & Air / Dust (outdoor) & 1 & 2 & 0 & 0 & 0 & 0 & 0 & 2 & 2 & 1 & 2 & 10 \\
\hline Su et al. (2020) [51] & Dust & 1 & 0 & 1 & 1 & 0 & 2 & 0 & 1 & 1 & 2 & 1 & 10 \\
\hline Peller et al. (2019) [52] & Air (outdoor) & 1 & 1 & 0 & 0 & 2 & 1 & 0 & 0 & 2 & 2 & 0 & 9 \\
\hline Dehghani et al. (2017) [53] & Dust & 1 & 0 & 1 & 2 & 0 & 1 & 0 & 1 & 2 & 0 & 1 & 9 \\
\hline Abbasi et al. (2019) [54] & Air / Dust (outdoor) & 2 & 1 & 0 & 2 & 0 & 0 & 0 & 1 & 2 & 0 & 1 & 9 \\
\hline Liu et al. (2019) [55] & Dust & 2 & 0 & 2 & 0 & 0 & 1 & 0 & 1 & 1 & 1 & 0 & 8 \\
\hline Tunahan et al. (2018) [18] & Air / Deposition / Dust (outdoor) & 1 & 1 & 2 & 0 & 0 & 0 & 0 & 0 & 1 & 1 & 1 & 7 \\
\hline Cai et al. (2017) [15] & Deposition & 2 & 1 & 1 & 0 & 0 & 0 & 0 & 0 & 1 & 1 & 1 & 7 \\
\hline Dris et al. (2015) [16] & Deposition & 2 & 1 & 0 & 1 & 0 & 1 & 0 & 0 & 1 & 0 & 1 & 7 \\
\hline Dris et al., (2017) [4] & Air (outdoor and indoor) / Deposition / Dust (indoor) & 1 & 1 & 0 & 0 & 0 & 0 & 0 & 1 & 1 & 1 & 1 & 6 \\
\hline Yukioka et al. (2020) [56] & Dust & 1 & 0 & 1 & 0 & 0 & 0 & 0 & 1 & 0 & 2 & 1 & 6 \\
\hline Syafei et al. (2019) [57] & Air (outdoor) & 2 & 0 & 0 & 0 & 0 & 0 & 0 & 0 & 1 & 1 & 0 & 4 \\
\hline Asrin et al. (2019) [58] & Air (outdoor) & 0 & 0 & 0 & 0 & 0 & 0 & 0 & 0 & 0 & 1 & 1 & 2 \\
\hline
\end{tabular}

${ }^{a}$ Evaluation Criteria: 1. Sampling methods; 2. Sample duration; 3. Sample processing and storage; 4. Laboratory preparation; 5 . Clean air conditions; 6 . Negative controls; 7. Positive controls; 8. Sample treatment; 9. Filter substrate; 10. Polymer identification; 11. Particle properties 


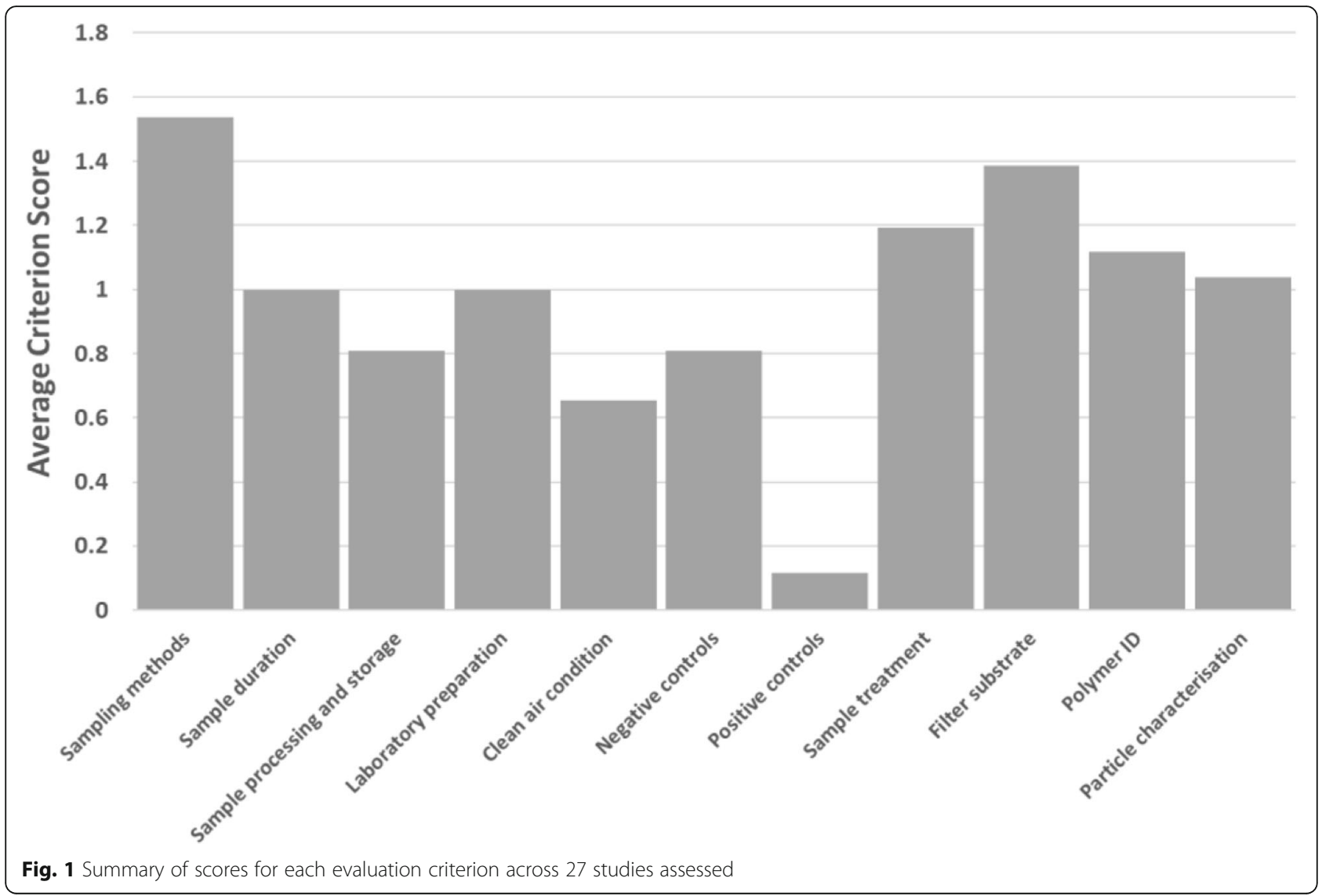

relevant deposition rates (i.e. $\mathrm{MPs} / \mathrm{m}^{2} / \mathrm{d}$ ). The application of duplicate samplers could also help strengthen understanding pertaining to local scale variation with respect to deposition rates.

The use of filtered water during sample collection is also identified as being important. Ideally ultrapure water or water that is filtered through a filter with a pore size that is below the particle size limit of detection for the method being employed (for instance, glass fiber filters with pore size of $0.45 \mu \mathrm{m}$ are often used), since the filter pore size directly influences the particle size detection limit possible for subsequent analysis. For a maximum score of 2, the sampler should be described, including the sample collection surface area and whether bulk or wet deposition is collected. Additionally, the location, date, sampler height, sampling duration and materials used (e.g. filtered water in sample collection) should be reported. Scores of 1 are assigned to studies that report only a subset of the required criteria (e.g., date, location, materials used), however is still reproducible. The height of the sampler is important to infer whether deposition is atmospheric or a combination of atmospheric deposition and re-suspension of ground level MPs. Resuspension might be reflective of local sources, whereas atmospheric deposition may indicate potential long-range transport and removal from the atmosphere. In the context of assessing human exposure particular attention will be required towards characterizing the particle size distribution of MPs, since this can influence potential differences between inhalation and oral exposure pathways.

To date, samples assessing MPs in air have been collected using a variety of samplers which actively pump air across a range of flow rates $(8-100 \mathrm{~L} / \mathrm{min})$. One study assessed the effect of sampling volume on MPs and found a statistically significant logarithmic relationship between sampling volume and MP abundance, predominantly driven by fibrous MPs [46]. Inter-sample variation (standard deviation) was observed to be reduced when sampling volume exceeded $72 \mathrm{~m}^{3}$. None of the studies reviewed employed an aerodynamic size-selective inlet, but one study (indoor) did use a Breathing Thermal Mannikin to simulate physiological influence on the boundary layer flow around the sampler [45]. This is important when measuring human exposure to indoor air contaminants, as most of the inhaled air is transported from lower regions of the room along the body to the mouth or nose [45]. For a maximum score of 2, the location, sampling instrument (make, model), aerodynamic size fraction sampled, flow rate, sampler height, filter 
substrate, sampling duration, and date should be reported.

Dust samples have been collected either directly from a vacuum cleaner bag or via sweeping a defined area of floor (outdoor or indoor). Snow samples [3] were collected by scooping the upper layers of freshly fallen snow, although it is not possible to differentiate between the fraction deposited wet and dry with this sample type. Similar challenges are also attributed to the use of biological media, such as moss [49], as a bioindicator of atmospheric deposition, since both are further complicated by limited potential to assess the duration since the particles had been deposited. For a maximum score of 2, location, sampling date, apparatus used, and the mass/area collected should be reported.

\section{Sample duration}

Sampling duration will differ depending on the sample type and research question. In some instances, deposition samples are collected at unequal intervals, depending on accumulative rainfall $[5,16]$, relative levels of dust [21] or access to sites [20]. Deposition samples are generally collected at monthly [15] or fortnightly [22, 47] intervals. This is typical for traditional bulk deposition measurements. Shorter resolutions will enable stronger interpretation with temporally resolved meteorological variables, whilst coarser resolutions will enable seasonal differences to be assessed. The minimum sampling duration will be dependent on the total MP deposition rates, for example, the duration needed to sample enough MPs to allow detection that is at least three times above the standard deviation of the blanks [59, 60].

The sampling duration of air samples is observed to be highly variable. For example, Dris et al. [5] collected indoor samples over inconsistent durations, although sampling time was adjusted to best coordinate with indoor activity, i.e. when people were in the home. Outdoor air samples, on the other hand, were collected over longer durations, presumably to reduce the risk of false negatives due to the low concentrations observed [5]. Dehghani et al. [53] collected samples at a relatively high flow rate $(300 \mathrm{~L} / \mathrm{min})$ over a short duration $(30 \mathrm{~min})$, as did Liu et al. [48] (1 h sampling duration at $100 \mathrm{~L} / \mathrm{min}$ ). Vianello et al. [45] collected $24 \mathrm{~h}$ samples, as is common in air quality monitoring. Evidently the sample duration will vary depending on the flow rate of the sampler, the nature of the sample (e.g., if highly polluted or high organic content) and the research question (e.g., if interested in a specific activity and/or a specific time of day). Liu et al. [46], however, recommend a sample volume of at least $70 \mathrm{~m}^{3}$ (approximately a $12 \mathrm{~h}$ sampling duration using a high volume sampler $(100 \mathrm{~L} / \mathrm{min}))$, whilst $24 \mathrm{~h}$ is typical for a PM10 sample collected with a low-volume sampler (EN 12341). Sampling duration is not relevant to dust as it is collected in a cross-sectional manner, with the concentration normalised to mass.

There are potentially several issues that might benefit from additional method development in relation to sampling air for MPs and ambient particles in general. The first relates to the potential for particle breakthrough. For instance, particles of a similar size to the filter pore size cutoff might penetrate the filter under higher flow rates. This might result in an underestimate of MP concentration in air. Alternatively, high particle loading of the filter can introduce resistance to air flow, influencing the relative accuracy of the volume of air estimated to have been sampled. Consequently, there is a need to ensure a balance between flow rate, filter substrate composition and sampling duration to avoid these issues, which have the potential to introduce inaccuracies in the actual volume of air sampled and/or the actual particle mass sampled.

\section{Sample processing and storage}

Depending on the type and nature of the sample, processing steps may not always be necessary (e.g. air [46, $48,55]$ ) and therefore a score of ' 2 ' is assigned automatically to studies where this criterion did not apply. In the included studies most deposition samples are collected using water and hence needed to be filtered in the laboratory via vacuum filtration. During the rinsing and filtration processes, there is the potential for either a loss or gain of MPs. Importantly, most of the included studies did not assess the recovery rate of positive controls during these steps, a fundamental QA/QC criterion. In the absence of positive controls it is therefore not possible to assess the relative performance of the method in relation to Type I and II errors.

The importance of sample storage has not yet been fully assessed in the literature. Whether plastic petri dishes contribute to microplastic contamination, and/or whether storage at room temperature, in the fridge or in the freezer is optimum for analysis whilst preserving the physicochemical characteristics of sampled MPs would benefit from additional research. Recent observations, for instance, have drawn attention to the role of electrostatic attraction between MPs and the glass of the petri dish, which can influence the loss of particles [61]. Consequently, efforts that attempt to address issues associated with sample handling and storage by adopting cold storage or conducting sample treatment immediately are scored more highly $(n=16)$ than those studies which do not provide any details regarding sample storage $(n=10)$.

\section{Laboratory preparation}

As previously outlined [34], laboratory preparation particularly best cleaning practices - is important for 
mitigating background microplastic contamination of samples and therefore the inclusion of false positives. A clean laboratory environment, with rigorous cleaning protocols for apparatus, focusing on a particle-free goal, is essential for analysis of MPs in air. Studies that adequately described methods to minimize MP contamination in the lab, including the use of cotton laboratory coats, plastic being avoided where possible (in the lab and/or reducing the use of plastic during sample collection and storage), reagents being filtered and glassware and all instruments being rinsed (ideally triple rinsed), sonicated and/or combusted are assigned a score of ' 2 ' $(n=11)$. If a good level of preparation was not indicated but laboratory and/or procedural blanks were included, then the study was scored ' 1 ' $(n=4)$. Several studies $(n=12)$ did not provide sufficient information to evaluate the potential of background lab contamination and thus were assigned a score of ' 0 '.

\section{Clean air conditions}

Maximum scores were awarded to those studies which used a clean room, clean bench or laminar flow hood $(n=6)$. Studies that included the adoption of practices aimed at protecting samples to minimize contamination from the air were assigned a score of ' 1 ' $(n=5)$. Eight studies were assigned a value of ' 0 ' for not providing any details on the handling of samples within clean air conditions and/or or report limited use of an open filter in a petri dish in the laboratory to monitor contamination.

\section{Negative controls}

Negative controls are blank samples collected to quantify and characterize the extent of background contamination. Contamination may arise during sample collection (e.g. from plastic components in the sampling device) and/or during sample processing. The use of blanks, collected throughout the sampling period (at least in triplicate), but without exposure to air/deposition, and laboratory/procedural controls, treated and analysed in parallel to samples, should be included. It is recommended that authors clearly state the application of blanks following analysis; sample concentrations should be corrected for results observed in the negative controls, deducting the baseline not only by count, but by shape and polymer type. Studies that mention procedural blanks but fail to provide all supporting information needed to determine how the data obtained from the blanks are applied, were assigned a score of ' 1 ' $(n=12)$. Four studies were assigned a score of ' 2 ', in that they included both lab and field blanks in sufficient numbers to enable a robust statistical analysis of the level of background contamination, blank correcting the sample concentrations accordingly. The relatively poor inclusion of blanks across several of the studies, however, and how the information is reported represents a general cause for concern. Generally, the inclusion of blanks should represent a fundamental and routine component of any QA/QC protocol, which is information that can be readily assessed as part of the sample collection and processing of air samples. It is unclear why negative controls are so poorly represented in the data reported, but this is a criterion that must be better addressed in future studies.

\section{Positive controls}

Despite the observation that many studies include various sample processing steps, such as washing and filtration, only two studies included the application of positive controls. Given the potential for microplastic loss during washing, filtration, digestion, density separation, etc., an indication of the method recovery efficiency is critical to infer the accuracy of results and conclusions. Only when samples are collected and directly analysed are processing controls not needed. It is thus recommended that microplastic analysis include routine checks to monitor recovery performance. Reference to method recovery efficiency, for instance, based on data published elsewhere is not sufficient to demonstrate that the method was similarly as efficient during the analysis of the samples being processed. Interlaboratory comparison studies [62] have documented significant variability between labs and it is anticipated that similar variability could also occur within the same lab between individuals and on different days. The lack of attention towards processing a positive control for samples processed in a particular study therefore results in a score of ' 0 '.

\section{Sample treatment}

Following sample collection or filtration, eight studies did not include any sample treatment, with the remaining studies using a digestion step followed by isolating MPs via density separation for deposition, air and dust samples.

For deposition samples, the digestion method was based on either $\mathrm{NaClO}$ (6-14\%, 0.15:1 ratio) for $24 \mathrm{~h}$ [22] or $\mathrm{H}_{2} \mathrm{O}_{2}(30 \%)$ at $55^{\circ} \mathrm{C}$ for $7 \mathrm{~d}+$ extra volume for 7 $\mathrm{d}$ [20]. Density separations were based on the use of $\mathrm{ZnCl}_{2}$ for $7 \mathrm{~d}$ [20]. For air samples $30-35 \% \mathrm{H}_{2} \mathrm{O}_{2}(8 \mathrm{~d})$ $[18,54]$ was used to digest samples and either $\mathrm{ZnCl}_{2}$ [18] or NaI [54] for MP density separation, allowing 90 min for settling of particles. Dust samples were digested using $30 \% \mathrm{H}_{2} \mathrm{O}_{2}(8 \mathrm{~d})[53,54]$ and separated using either $\mathrm{ZnCl}_{2}(1.6)[4,53,55]$ or $\mathrm{NaI}[54]$.

For studies where a digestion step was necessary, a score of ' 2 ' is assigned where the impact of the digestion method on different polymers has been assessed and where incubation temperatures are $<50{ }^{\circ} \mathrm{C}[34,63]$, 
identified as being important for ensuring that damage to MPs or changes in glass transition temperature have not occurred. Most studies, however, used temperatures $>50^{\circ} \mathrm{C}$, and were assigned a score of ' 1 ' or provided insufficient information to fully evaluate how the samples were treated, receiving an evaluation score of ' 0 '.

\section{Filter substrate}

It is strongly recommended that a flat membrane filter or substrate is used to enhance optical contrast for visual assessment and downstream micro-spectroscopic analysis. Most studies use glass or quartz fibre filters for visual analysis $[4,15,16,46,48,55]$. The use of glass or quartz fibre filters is problematic because of the potential for small particles to become embedded and/or hidden within spaces between fibres, causing the identification of MPs and fibres to be generally difficult against a fibrous matrix. Thus, studies that use flat membrane filters comprised of cellulose $[18,22,47,53$, 54], aluminium oxide [3,20] or other flat substrates [45] are assigned the highest score. The choice of filter/substrate composition is also important depending on whether analysis will be performed directly in the sample without transfer. For example, a cellulose filter loaded with (mostly black) PM may burn under relatively low laser powers during spectroscopy and its signal may interfere and effect signal-to-noise ratio, such as during micro-spectroscopy [64].

\section{Polymer characterization (including identification)}

All studies that conducted polymer analysis used infrared and near infrared spectroscopy (FTIR or Raman) approaches. These analytical methods can be automated, semi-automated or operator based. Operator-based approaches typically involve the analysis of a subsample of suspected MPs to determine the success rate of the overall method in accurately identifying MPs. This is then extrapolated to the entire sample count. Hermsen et al. [36] recommended that analysis of all particles is feasible for samples containing $<100$ suspected MPs per study. For studies with $>100$ particles, $50 \%$ should be characterized using an analytical approach [34]. If analysis is based on a per sample basis, it is recommended that all suspected MPs be analyzed, with a defined minimum of $50 \%$ of particles analyzed for samples with $>100$ suspected MPs [34]. The minimum of $50 \%$ of suspected MPs is recommended in that it is the perceived minimal amount defined as enabling a representative assessment of the 'average' or 'typical' characteristics related to the variety of shapes and polymer types associated with the sample, with increasing confidence in the quality of the data increasing with the fraction of suspected MPs analyzed.
Studies that have been assigned the highest score included a detailed and reproducible analytical method, including a description of whether the suspected MPs were directly analysed in a sample or manually transferred to a new substrate. The distribution of analysed particles across samples and a high hit quality ratio (at least $>70 \%)$ to identify spectra using a reference library is also an important component reflective of studies being assigned a value of ' 2 '. Intuitively, the specific details of the library/database or software/programme should be included as part of the description. Optimally, polymer identification should be either automated or semiautomated, to eliminate operator bias. Bergmann et al. [3] was the only study to score 2, using FPA - $\mu$ FTIR-Imaging. Five studies were assigned a value of ' 0 ' for not performing an accepted polymer analysis. Studies were assigned a value of ' 1 ' if no information regarding how spectra were matched was reported; the total number of particles and fibres analysed represented $<50 \%$ of the total sample and/or how the analysed particles and fibres were distributed across samples and their overall representativeness to the total was not reported; low HQIs were used to ID (<70\%); or polymer-only spectral libraries were used, as this could infer bias $[4,5,15,18,20$, $22,45,46,48,55]$.

Generally, the primary challenge associated with polymer identification is that the relative resource needed to strengthen the quality of results represents a significant time intensive component of the overall analysis. Future research aimed at routine monitoring will thus require availability of robust high throughput methods. Importantly, even when considering the relative success rate of suspected MPs in a sample, it is not possible to conclude with $100 \%$ confidence that the observations in the analyzed fraction of the sample can be extrapolated to the total sample, it is thus difficult to report results quantitatively with a high degree of certainty. Intuitively, the higher the number of particles analyzed in a sample the more robust inferences can be made regarding the quantitative value of the data and can thus help to reduce any potential uncertainties - a suggestion that has recently been supported quantitatively by chemometric analysis [65]. Even so, this is a best estimate without knowledge of the true number of MPs in a sample, since spectral quality and subsequent identification may be limited or erroneous, due to particle surface coatings.

\section{Discussion and guidance}

While concern regarding human exposure of MPs in drinking water, food and food packaging has grown recently, identification of the presence of MPs in air is emerging $[5,6,14,17-19,24,66-69]$. As with the contamination of surface waters by MPs, the concentrations of MPs in the atmosphere will be subject to spatial and 
temporal variability, with emissions to the atmosphere influenced by differences in the relative magnitude of sources (such as differences between industrial/urban locations versus emissions from remote locations) and processes that influence atmospheric transport and mobility (i.e. wet and dry deposition, air speed and direction) $[3,6,20,22,23]$.

The primary processes and sources emitting MPs to air have previously been hypothesized to be the degradation and fragmentation of textiles $[4,5]$ and tire abrasion (tire road wear, TRW) $[3,7-9,70]$. There are a variety of additional sources that can also contribute to presence in air, indicated by the presence of fragments, and variance in the dominant shapes of MPs that can vary depending on the location, sample type and size class. The inherent variability associated with existing data can thus make it difficult to draw definitive conclusions regarding sources and characteristics of MPs in air. Research is thus needed to address the inherent complexities and limitations related to the availability of high quality data reporting MPs in air and the paucity of knowledge regarding the relative contribution of processes and sources of MPs to the total particulate loading, as represented by measurements of PM. Consequently, guidance with respect to best practices regarding QA/QC that adhere to the criteria outlined above is urgently needed.

Particulate matter in air can be characterized and quantified using a variety of methods available that are capable of actively pumping from low to high volume flow rates. As reviewed and summarized by Enyoh et al. [6] the methods differ depending on the target contaminant and research question. Importantly for MPs, none of the available methods can currently provide online monitoring capable of discriminating and differentiating MPs from other types of PM. Air samples must therefore be collected and analysed retrospectively.

Existing sampling methods used for gravimetric PM measurements are amongst the appropriate tools for assessing concentrations of MPs in air, as they collect particulates onto a substrate which can be retrospectively analysed. These include low- and high-volume air samplers fitted with a size selective inlet head (e.g. PM10) and which include a filter substrate and regulated flow controller (e.g. Kleinfiltergerat and Partisol samplers). Another widely used sampling method is the Tapered Element Oscillating Microbalance (TEOM), which collects a sample onto a tape whilst providing real-time short resolution gravimetric data, although this feature would only be useful if MP concentrations are to be assessed for a short-time resolution and therefore occur at high enough concentrations to detect them over short sampling durations.
Standard guidelines are available for mass-based PM measurements, such as the European Committee for Standardization (CEN) EN 12341, and could be used for the purpose of contextualising MP concentrations in air and understanding their mass contribution, such as in the case of mass-based analysis using pyrolysis- and thermal desorption-GCMS to measure the mass of synthetic polymers consistent with MPs [71]. Other sampling options for characterizing and quantifying MPs in air include cascade impactors, which collect and separate PM on impaction substrate filters or discs across an aerodynamic size distribution, cyclone samplers and liquid impingers. The sample duration using the various methods will be influenced by the volume of air to be sampled and the relative level of PM in the air. Where sensitivity is not likely to represent a concern and/or longer sampling times are required, low-volume air samplers $(\approx 17 \mathrm{~L}$ air/hour) represent an appropriate tool. Where sensitivity may represent an issue or in instances where larger volumes of air are required to be sampled, such as sampling over shorter temporal resolution, highvolume air samplers $\left(\approx 70 \mathrm{~m}^{3}\right.$ air/h) may be more appropriate. Finally, the use of portable personal samplers, may provide estimates of exposure at the individual level, or through the use of low- and high-volume personal air samplers using conventional impactor or cyclone technologies, may be beneficial in providing integrated daily, or longer, measurements of sizeseparated PM fractions.

In all sampling methods there is always a risk of contamination due to plastic components in the instruments themselves as well as external variables related to background contamination and human error. The systematic collection of blanks is therefore recommended, such as field blanks, collected alongside samples collected in the field at predefined intervals (e.g. 1 field blank every 3rd sample). Additionally, travel blanks may also be included to assess contamination during transport and handling of the samples, whereas laboratory blanks, collected to evaluate background contamination during the processing and analysis of samples, should represent standard QA/QC procedure in all MP measurement studies.

Related to the collection of blanks is the need to quantify limits of detection more robustly. The limit of detection (LOD) is the lowest concentration level that can be determined to be statistically different from an analytical blank and has been adopted by the International Union of Pure and Applied Chemistry (IUPAC) as a standard model for reporting concentrations of trace elements or chemicals in various sample matrices for several decades [60]. The general approach adopted is to calculate the LOD as three times the standard deviation of the blank value, which requires the processing of a sufficient number of blanks in order to derive a statistically meaningful 
standard deviation [59,60]. For studies processing $<3$ blank samples as part of their analysis, a robust estimate of the standard deviation is simply not possible. The general approach to blank correct samples has thus become a practice of subtracting the (average) number of particles observed in the blank(s) from the sample. When no particles are observed in the blank, authors suggest that background contamination is not an issue, and no correction to the data is employed. We suggest that the observation of producing a 'zero' blank based on a limited number of blanks should be challenged and that efforts to calculate and report the LOD, as well as the limit of quantification (LOQ; 10x the standard deviation), should be more widely applied (see for instance Ball et al. [72]). Closely related to the LOD is the method detection limit (MDL). For MPs, the MDL would represent the lowest particle size/shape that can be analysed. The particle size MDL may be confined based on the pore size of the filter used in collecting and/or filtering the sample, but also might be confined to analytical limitations, in that methods such as Raman and FTIR microscopy, used to verify polymer composition have a minimum spatial resolution. The particle size MDL thus needs to be considered relative to the LOD. Including QA/QC protocols that enable the calculation and reporting of parameters, such as the LOD, LOQ and MDL in future studies can only help strengthen the interpretation of future data.

A caveat to filter-based sampling is that downstream compositional analysis is required. Typically for MPs this is achieved via micro-spectroscopy (Raman or Fouriertransform infrared) either operator-based, semiautomated, or automated. Careful selection of the analyte substrate to avoid analytical signal interference or disintegration during processing, such as in the case of organic substrates, should be considered, depending on whether samples will be directly analysed on the filter or extracted and processed first. Liquid impingers represent an option that eliminates the need for a sample substrate, reducing the handling time of the sample. A disadvantage, however, is related to the extent of evaporation that can occur during sampling, which needs to be considered and assessed. Viscous, nonevaporative liquids, such as mineral oil, are typically recommended for collection, although these types of liquids might hinder and interfere with downstream analysis.

Given the relative recent interest in characterizing and quantifying MPs in air, there are several uncertainties with respect to method development that need to be addressed. For instance, except for tire wear, there are no published data reporting on the aerodynamic size distribution of MPs in air. It is important to evaluate the aerodynamic size distribution range of MPs to help guide the adoption of appropriate monitoring tools, such as differences between using instrumentation that targets TSP versus those capable of differentiating particle-size fractions. If MPs are observed to be present in size fractions that have implications towards human health, then larger scale monitoring programmes to evaluate spatial and temporal variation would thus be warranted, which could be readily integrated into existing air quality monitoring and modelling networks. Furthermore, depending on more refined understanding of the relative levels of MPs in air, personal exposure assessments may be warranted, with the objective of reducing uncertainties in an individual's MP exposure relative to different activities and microenvironments (such as differences between home, work and outdoor exposure).

There are several studies reporting the presence of MPs in air based on the analysis of bulk deposition samples (Table 3), and which do not enable estimates of inhalation exposure to be derived via a volume of air. An example of a study that does attempt to estimate inhalation exposure to MPs from deposition data, however, is that of Liu et al. [48], who estimate an inhalation exposure of $21 \mathrm{MPs} / \mathrm{d}$ for individuals living in Shanghai, China. The size range of the particles, however, is reported to range between 23.07 and $9955 \mu \mathrm{m}$, with an average of $597.5 \mu \mathrm{m}$ [48], suggesting that the estimate of daily inhalation exposure based on monitoring data of relatively large MPs should be interpreted with caution. Nevertheless, while particles $>100 \mu \mathrm{m}$ in aerodynamic diameter are known to have lower probabilities of entering the nasal passage [73], the data are still valuable for providing a relative indication of human exposure of MPs from air, for which oral ingestion may be relevant. For instance, particle concentration and composition of MPs $>100 \mu \mathrm{m}$, for which inhalation exposure is less likely, and that may deposit onto food or otherwise be ingested along with dust can be quantified and characterized.

Table 3 summarizes data on MPs in air reported in studies included in this review. As shown in Table 2, the only study to receive no 'zero' scores is the study by Wright et al. [42], who report MPs in atmospheric deposition collected in London, UK, during January and February 2018. Wright et al. [42] report a dominance of fibres observed in deposition samples, with fibres having diameters ranging from between 5 and $75 \mu \mathrm{m}$ with most lengths being $400-500 \mu \mathrm{m}$. The most abundant nonfibrous particles were between 75 and $100 \mu \mathrm{m}$, with the smallest particle being $25 \mu \mathrm{m}$, consistent with the lower size particle that could be identified based on the method used [42]. Deposition rates are estimated to range from between 575 to $1008 \mathrm{MPs} / \mathrm{m}^{2} / \mathrm{d}$. Based on the particle sizes reported by Wright et al. [42], i.e. > $25 \mu \mathrm{m}$, inhaled particles are likely to deposit in the upper airway and be swallowed, implying potential concern 
Table 3 Summary of studies with TAS > 10 for MPs reported in indoor and outdoor air for both urban and rural locations

\begin{tabular}{|c|c|c|c|c|c|c|c|c|}
\hline Author & $\begin{array}{l}\text { Sample } \\
\text { type }\end{array}$ & $\begin{array}{l}\text { Lower } \\
\text { size limit } \\
(\mu \mathrm{m})\end{array}$ & $\begin{array}{l}\text { Particle } \\
\text { concentration } \\
\text { (average) }\end{array}$ & $\begin{array}{l}\text { Particles in } \\
\text { blanks } \\
\text { (average) }\end{array}$ & Particle size $(\mu \mathrm{m})$ & $\begin{array}{l}\text { Predominant } \\
\text { particle } \\
\text { shape }\end{array}$ & $\begin{array}{l}\text { Predominant } \\
\text { polymer type }\end{array}$ & $\begin{array}{l}\text { Quality } \\
\text { score } \\
\text { (TAS) }\end{array}$ \\
\hline $\begin{array}{l}\text { Wright } \\
\text { et al. [42]) }\end{array}$ & Deposition & 20 & $\begin{array}{l}712 \text { fibers } / \mathrm{m}^{2} / \mathrm{d} \\
59 \text { Non-fiber } \\
\text { particles } / \mathrm{m}^{2} / \mathrm{d}\end{array}$ & $\begin{array}{l}3 \text { cellulose } \\
\text { fibres }\end{array}$ & $\begin{array}{l}\text { Fibre diameters of } \\
\text { between } 5 \text { and } 75 \\
\text { and most abundant } \\
\text { length } 400-500 \text {, } \\
\text { average } 905 . \text { Average } \\
\text { of non-fibrous parti- } \\
\text { cles is } 164 \text {. }\end{array}$ & Fibres & $\begin{array}{l}17 \% \text { of fibres synthetic, } \\
\text { dominated by PAN, } \\
\text { PET, and Polyamide. } \\
69 \% \text { of fibres identified } \\
\text { as cellulose. }\end{array}$ & 18 \\
\hline $\begin{array}{l}\text { Gaston } \\
\text { et al. [43] }\end{array}$ & $\begin{array}{l}\text { Air (both in } \\
\text { and } \\
\text { outdoor) }\end{array}$ & 20 & $\begin{array}{l}3.3 \text { fibres and } \\
12.6 \text { fragments/ } \\
\mathrm{m}^{3} \text { (indoor); } 0.6 \\
\text { fibres and } 5.6 \\
\text { fragments } / \mathrm{m}^{3} \\
\text { (outdoor) }\end{array}$ & $\begin{array}{l}2.4 \text { fibres and } \\
12.2 \text { fragments } \\
\text { per filter } \\
\text { (indoor) per } \\
\text { filter; } 0.4 \text { fibres } \\
\text { and } 6.3 \\
\text { fragments } \\
\text { (outdoor) per } \\
\text { filter }\end{array}$ & $\begin{array}{l}\text { Fibres lengths indoor } \\
641 \mu \mathrm{m} \text {; outdoor } \\
616 \mu \mathrm{m} \text {; approx. } 30 \% \\
\text { of fibres between } 100 \\
\text { and } 300 \mu \mathrm{m} \text {; } \\
\text { Fragments outdoor } \\
104 \mu \mathrm{m} \text {; indoor } \\
58.6 \mu \mathrm{m} \text {. }\end{array}$ & Fragments & PS, PET, PE & 15 \\
\hline $\begin{array}{l}\text { Wang } \\
\text { et al. [44] }\end{array}$ & Deposition & $\begin{array}{l}\text { Not } \\
\text { defined }\end{array}$ & $1 \mathrm{MP} / 100 \mathrm{~m}^{3}$ & Not reported & $\begin{array}{l}851.09 \pm 578.30 \\
\text { Fibers: measured } \\
\text { between } 288.20 \mu \mathrm{m} \\
\text { and } 2251.54 \mu \mathrm{m} \\
(935.94 \pm 556.63 \mu \mathrm{m}) \\
\text { in length }\end{array}$ & 88.89\% fibres & $\begin{array}{l}77 \% \text { of natural origin, } \\
21 \% \text { plastic. Natural } \\
\text { particles mainly cotton } \\
\text { and cellulose, artificial } \\
\text { fibers of rayon (50\%) } \\
\text { and cellophane. Other } \\
\text { particles were PE, PET, } \\
\text { PP. }\end{array}$ & 15 \\
\hline $\begin{array}{l}\text { Klein and } \\
\text { Fischer } \\
{[22]}\end{array}$ & Deposition & 50 & $\begin{array}{l}275 \mathrm{MPs} / \mathrm{m}^{2} / \mathrm{d} \\
\text { range } 136.5 \text { to } \\
512 \mathrm{MPs} / \mathrm{m}^{2} / \mathrm{d}\end{array}$ & $\begin{array}{l}7.3 \pm 4.8 \mathrm{MPs} / \\
\text { blank }\end{array}$ & $\begin{array}{l}\text { fibes ranged between } \\
300 \text { and } 5000 \mu \mathrm{m} ; \\
\text { fragments }<63 \mu \mathrm{m} \text {. }\end{array}$ & $\begin{array}{l}95 \% \text { of } \\
\text { particles } \\
\text { identified as } \\
\text { fragments }\end{array}$ & $\begin{array}{l}\text { PE (49\%), ethylene } \\
\text { vinyl acetate } \\
\text { copolymer (22\%). }\end{array}$ & 15 \\
\hline $\begin{array}{l}\text { Bergmann } \\
\text { et al. [3] }\end{array}$ & Snow & 11 & $\begin{array}{l}\text { Non-fibrous: } \\
9.8 \times 10^{3} \mathrm{MPs} / \mathrm{L} \\
\text { fibres: } 0.043 \times \\
10^{3} \text { to } 10.2 \times \\
10^{3} \mathrm{MPs} / \mathrm{L}\end{array}$ & $\begin{array}{l}\text { Vary from } 256 \\
\text { to } 27,243 \mathrm{MPs} / \mathrm{L} \\
\text { (samples blank } \\
\text { corrected) }\end{array}$ & $\begin{array}{l}80 \% \leq 25 \mu \mathrm{m}, 98 \%< \\
100 \mu \mathrm{m} ; \text { particle } \\
\text { range } 11 \text { to } 475 \mu \mathrm{m} . \\
\text { Fibre lengths range } \\
\text { from } 65 \text { to } 14,314 \mu \mathrm{m}\end{array}$ & $\begin{array}{l}\text { Fibres - both } \\
\text { natural and } \\
\text { synthetic, with } \\
\text { MPs } \\
\text { accounting for } \\
12 \% \text { of } \\
\text { particles on } \\
\text { average. }\end{array}$ & $\begin{array}{l}\text { Acrylates, } \\
\text { polyurethane, varnish } \\
\text { most frequently } \\
\text { detected }\end{array}$ & 15 \\
\hline $\begin{array}{l}\text { Vianello } \\
\text { et al. [45] }\end{array}$ & Air (indoor) & 11 & $\begin{array}{l}9.3 \pm 5.8 \\
\text { particles } / \mathrm{m}^{3}\end{array}$ & $\begin{array}{l}7.7 \pm 3.8 \mathrm{MPs} / \\
\text { blank: data not } \\
\text { corrected }\end{array}$ & $\begin{array}{l}36 \text { and } 21 \text { for the } \\
\text { major and minor } \\
\text { dimension }\end{array}$ & $\begin{array}{l}13 \% \text { fibres } \\
87 \% \\
\text { fragments }\end{array}$ & $\begin{array}{l}81 \% \text { PES, } 6 \% \text { PE, } 5 \% \\
\text { PA, } 2 \% \text { PP, and } 6 \% \\
\text { other polymers; non- } \\
\text { synthetic - } 95 \% \text { pro- } \\
\text { tein, } 5 \% \text { cellulose; MPs } \\
=>4 \% \text { total particles }\end{array}$ & 14 \\
\hline $\begin{array}{l}\text { Liu et al. } \\
\text { [46] }\end{array}$ & $\begin{array}{l}\text { Air } \\
\text { (outdoor) }\end{array}$ & 12 & $\begin{array}{l}0.41 \mathrm{MPs} / \mathrm{m}^{3}(0 \\
\left.\text { to } 2 \mathrm{MPs} / \mathrm{m}^{3}\right)\end{array}$ & $\begin{array}{l}\text { no MPs in one } \\
\text { blank collected }\end{array}$ & $\begin{array}{l}246.52 \mu \mathrm{m}(12.35 \text { to } \\
2191.32 \mu \mathrm{m})\end{array}$ & $\begin{array}{l}\text { Fibres }(43 \%) \text {, } \\
\text { fragments } \\
(48 \%) \text {, beads } \\
(9 \%)\end{array}$ & $\begin{array}{l}\text { PET }(51 \%), \text { epoxy resin } \\
(19 \%), \text { PE }(12 \%) \text {, and } \\
\text { alkyd resin }(8 \%) ; \\
\text { fibrous PET }=87 \%\end{array}$ & 13 \\
\hline $\begin{array}{l}\text { Stanton } \\
\text { et al. [47] }\end{array}$ & Deposition & 38 & $\begin{array}{l}\text { Max of } 2.9 \\
\text { fibres } / \mathrm{m}^{2} / \mathrm{d}\end{array}$ & $\begin{array}{l}\text { Synthetic fibres } \\
\text { not detected in } \\
\text { blanks }\end{array}$ & Not reported & $100 \%$ fibres & $2.1 \%$ synthetic & 13 \\
\hline $\begin{array}{l}\text { Allen et al. } \\
\text { [20] }\end{array}$ & Deposition & 10 & $\begin{array}{l}365 \pm 69 \\
\text { particles/m²/d } \\
\text { (range } 297 \text { to } \\
462 \text { ) }\end{array}$ & $\begin{array}{l}3 \pm 1 \text { fibres, } 1 \pm \\
1 \text { film and } 8 \pm 1 \\
\text { fragments per } \\
\text { filter }\end{array}$ & $\begin{array}{l}\text { majority MPs < } \\
50 \mu \mathrm{m} \text {, predominant } \\
\text { fibre lengths of 100- } \\
200 \mu \mathrm{m} \text { and 200- } \\
300 \mu \mathrm{m} \text { (max. } \\
3000 \mu \mathrm{m} \text { ), films 50- } \\
200 \mu \mathrm{m} \text {. }\end{array}$ & $\begin{array}{l}\text { Fragments }> \\
\text { fibres }>\text { films }\end{array}$ & $\begin{array}{l}\text { PS (as fragments) } \\
\text { followed by PE }\end{array}$ & 12 \\
\hline $\begin{array}{l}\text { Liu et al. } \\
\text { [48] }\end{array}$ & $\begin{array}{l}\text { Air } \\
\text { (outdoor) }\end{array}$ & $\begin{array}{l}\text { Not } \\
\text { reported }\end{array}$ & $\begin{array}{l}1.42 \pm 1.42 \\
\mathrm{MPs} / \mathrm{m}^{3}\end{array}$ & Not reported & $\begin{array}{l}582.2 \mu \mathrm{m} \text { range } \\
\text { between } 23.07 \text { to } \\
9555 \mu \mathrm{m}\end{array}$ & $\begin{array}{l}\text { Fibres (67\%); } \\
\text { Fragments } \\
\text { (30\%); } \\
\text { granules (3\%) }\end{array}$ & $\begin{array}{l}\mathrm{PET}, \mathrm{PE} \text {, and polyester } \\
\text { comprised } 49 \%\end{array}$ & 11 \\
\hline Dris et al. & Deposition & 50 & $110 \pm 96$ MPs/ & 1-2 fibres/filter & Fibre length 50- & $100 \%$ fibres & $17 \%$ synthetic (PET and & 11 \\
\hline
\end{tabular}


Table 3 Summary of studies with TAS > 10 for MPs reported in indoor and outdoor air for both urban and rural locations (Continued)

\begin{tabular}{|c|c|c|c|c|c|c|c|c|}
\hline Author & $\begin{array}{l}\text { Sample } \\
\text { type }\end{array}$ & $\begin{array}{l}\text { Lower } \\
\text { size limit } \\
(\mu \mathrm{m})\end{array}$ & $\begin{array}{l}\text { Particle } \\
\text { concentration } \\
\text { (average) }\end{array}$ & $\begin{array}{l}\text { Particles in } \\
\text { blanks } \\
\text { (average) }\end{array}$ & Particle size $(\mu \mathrm{m})$ & $\begin{array}{l}\text { Predominant } \\
\text { particle } \\
\text { shape }\end{array}$ & $\begin{array}{l}\text { Predominant } \\
\text { polymer type }\end{array}$ & $\begin{array}{l}\text { Quality } \\
\text { score } \\
\text { (TAS) }\end{array}$ \\
\hline [5] & & & $\begin{array}{l}\mathrm{m}^{2} / \mathrm{d} \text { (urban } \\
\text { site); } \\
53 \pm 38 \mathrm{MPs} / \\
\mathrm{m}^{2} / \mathrm{d} \\
\text { (suburban site) }\end{array}$ & & $\begin{array}{l}5000 \mu \mathrm{m} \text { (most 200- } \\
400 \mu \mathrm{m} \text { ); diameter 7- } \\
15 \mu \mathrm{m}\end{array}$ & & $\begin{array}{l}\text { polyamide); } 21 \% \\
\text { cellulose; } 12 \% \text { mix of } \\
\text { natural and synthetic }\end{array}$ & \\
\hline $\begin{array}{l}\text { Zhang } \\
\text { et al. [24] }\end{array}$ & $\begin{array}{l}\text { Dust } \\
\text { (indoor) }\end{array}$ & 150 & $\begin{array}{l}\text { PET-based MPs } \\
\text { ranged from } \\
\text { between } 29 \\
\text { and } 110,000 \\
\mu \mathrm{g} / \mathrm{g} \\
\mathrm{PC} \text {-based MPs } \\
\text { ranged from } \\
\text { between }< \\
0.11-1700 \mu \mathrm{g} / \mathrm{g}\end{array}$ & $\begin{array}{l}\text { MQLS of PET } \\
\text { and PC were } \\
5.3 \text { and } 0.11 \\
\mu \mathrm{g} / \mathrm{g}\end{array}$ & Not reported & Not reported & $\begin{array}{l}\text { Main focus on PET and } \\
\text { PC based polymers. }\end{array}$ & 11 \\
\hline $\begin{array}{l}\text { Roblin and } \\
\text { Aherne } \\
\text { [49] }\end{array}$ & $\begin{array}{l}\text { Deposition } \\
\text { (Moss) }\end{array}$ & 30 & 0.6 fibres/g & 24 fibres/g & $\begin{array}{l}\text { Fibres ranged } \\
\text { between 0.03-30.25 } \\
\mathrm{mm} \text {; average is } 1.02 \\
\mathrm{~mm} \text { across all sites. } \\
65 \%<0.8 \mathrm{~mm} .\end{array}$ & $100 \%$ fibres & Not reported & 11 \\
\hline $\begin{array}{l}\text { Li et al. } \\
\text { [50] }\end{array}$ & $\begin{array}{l}\text { Air } \\
\text { (outdoor) }\end{array}$ & $\begin{array}{l}\text { Fibres with } \\
\text { length }> \\
5 \mu \mathrm{m} \text { and } \\
\text { diameter }> \\
3 \mu \mathrm{m}\end{array}$ & $\begin{array}{l}5.7 \times 10^{-3} \\
\text { fibres } / \mathrm{ml}\end{array}$ & $\begin{array}{l}1 \times 10^{-4} \text { fibres/ } \\
\mathrm{ml}\end{array}$ & $\begin{array}{l}\text { Range between } 5 \\
\text { and } 20 \mu \mathrm{m}\end{array}$ & & $\begin{array}{l}34.6 \% \text { total fibres as } \\
\text { microplastic }\end{array}$ & 10 \\
\hline $\begin{array}{l}\text { Su et al. } \\
\text { [51] }\end{array}$ & $\begin{array}{l}\text { Dust } \\
\text { (Road) }\end{array}$ & 20 & $\begin{array}{l}\text { range between } \\
20.6 \text { to } 529.3 \\
\text { particles/kg }\end{array}$ & 5.6 particles/kg & $\begin{array}{l}\text { Range between } 0.08- \\
4.7 \mathrm{~mm} \text {; average } 1.2 \\
\mathrm{~mm}\end{array}$ & $\begin{array}{l}45.7-100 \% \\
\text { fibres }\end{array}$ & $\begin{array}{l}58.6 \% \text { plastic polymers } \\
\text { of polyester, PP and } \\
\text { rayon. Cotton and } \\
\text { cellulose account for } \\
65.4 \% \text { of non-plastic } \\
\text { particles }\end{array}$ & 10 \\
\hline
\end{tabular}

regarding oral ingestion, insight with respect to inhalation exposure, however, cannot be extrapolated from the data presented.

For those studies with a TAS $>10$, there is a mixture of studies reporting on MPs measured in atmospheric deposition, indoor and outdoor air, indoor and outdoor dust, and in snow and moss, which indirectly assess the impact of atmospheric deposition due to long-range transport of MPs. A general observation is that there are a limited number of studies reporting particle sizes < $50 \mu \mathrm{m}$, with several studies reporting a dominance of particles $>50 \mu \mathrm{m}$ (Table 3). For instance, Wright et al. [42] report the average size of non-fibrous particles as $164 \pm 167 \mu \mathrm{m}$, with particles ranging between 75 and $100 \mu \mathrm{m}$ representing the most abundant size range; Gaston et al. [43] report that $30 \%$ of fibres to be between 100 and $300 \mu \mathrm{m}$, with the average particle fragment size of $104 \mu \mathrm{m}$ in outdoor air and $58.6 \mu \mathrm{m}$ in indoor air; the average particle size reported by Wang et al. [44] is $851 \mu \mathrm{m}$; an average of $582 \mu \mathrm{m}$ and $246 \mu \mathrm{m}$ is reported by Liu et al. [46, 48], respectively; Dris et al. [5] report that most fibres detected had lengths between 200 and $400 \mu \mathrm{m}$. The particle size distributions reported, however, are biased by the analytical method employed, with the magnification of the microscope used strongly influencing results. Methods that apply an increased level of magnification, coupled with an appropriate analytical method, such as Raman microscopy, will enable lower size particles to be detected. Consequently, the variability in particle sizes reported do not necessarily reflect the particle size distribution actually present in the air, but are an artefact of the analytical capabilities used in the study itself.

In several studies, fibres are reported as the dominant shape of MPs observed, with diameters ranging from 5 to $75 \mu \mathrm{m}$. Several studies also report a dominance of fragments, with sizes ranging from between $<10 \mu \mathrm{m}$ to $>2 \mathrm{~mm}$. In some instances, particles $<50 \mu \mathrm{m}$ are reported as dominating the size fraction observed, such as by Allen et al. [20] and Bergmann et al. [3]. There thus appears to be considerable variability in the shapes and sizes reported in the literature, influenced by various factors, with inconsistencies in sampling, sample preparation and analysis methods representing the major factors. The development and application of standard methods are thus needed to strengthen the characterization and quantification of MPs in air and improve our understanding. 
With the objective of working towards better characterization of indoor human inhalation exposure, Vianello et al. [45], collected samples from three apartments in Aarhus, Denmark using a Breathing Thermal Manikin. The mannequin was used to simulate the presence of a human occupant in the apartment and included an inlet at the mouth that was connected to a low-volume air pump. Samples were collected on filters that were then analysed by $\mu$ FTIR, with a lower instrumental size LOD of $11 \mu \mathrm{m}$. Results suggest a ubiquitous presence of MPs in inhaled indoor air, with concentrations ranging from 1.7 particles $/ \mathrm{m}^{3}$ to 16.2 particles $/ \mathrm{m}^{3}$, with the most abundant polymers present consisting of polyester (59-92\%), polyethylene (5-28\%), nylon (013\%) and polypropylene 90.4-10\%) [45]. The concentrations of non-synthetic particles are reported as being 12 orders of magnitude higher. Fibres represented $13 \%$ of MPs identified, with $87 \%$ being fragments [45]. A nonnormal MP size distribution is observed with median values of $36 \mu \mathrm{m}$ and $21 \mu \mathrm{m}$ for the major and minor dimensions of particles. The daily MP exposure, estimated based on the maximum concentration measured, is 272 particles/d, approximately 10 times greater than reported for outdoor air in Shanghai. Considering that people spend most of their time indoors, inhalation of indoor air likely represents an important exposure pathway, however, due to the LOD of $11 \mu \mathrm{m}$, the exposure and impact of MPs in the central and distal airways remains poorly understood.

While the data summarized in Table 3 provides a relative indication regarding the ubiquity of MPs in both indoor and outdoor air, the sampling methods and the manner in which the data are reported result in challenges when attempting to interpret potential implications in relation to human health. For instance, inconsistencies with respect to units and lack of standardized sampling methods introduce difficulties when comparing studies and for extrapolating to assessing human exposure [74]. The data, however, imply that air represents a potentially important pathway for MP exposure. Given that none of the methods report concentrations of MPs $<5 \mu \mathrm{m}$, limited insight can be gained in helping to inform exposure via inhalation and therefore risk assessment. The sizes of MPs characterized in deposition studies can provide insight regarding oral ingestion, either as a result of the direct ingestion of dust or as a consequence of dust settling on food at different times throughout all stages of its collection, manufacturing, packaging, distribution and preparation. Currently, there is only one study that has estimated the importance of air to contaminate food with MPs [35]. Given the ubiquitous detection of MPs associated with atmospheric deposition, future research is recommended to improve assessing overall exposure due to air contamination and prioritizing key stages where MPs might be introduced as contaminants into food. As in previous studies evaluating the quality of microplastic research [34, 36, 37], it is important to emphasize that the scores assigned to each study should not be perceived as a judgement indicative of the relative value that a particular study represents to the field of microplastic research. Studies that receive low scores on various criteria can still provide valuable mechanistic and/or semiquantitative insight regarding the potential sources, fate and transport of MPs in air. Our main objective in the evaluation presented here largely relates to screening the existing data with respect to its potential use for assessing human exposure, thereby raising awareness of the various concerns that influence the ability to apply the data within that context. To be fit-for-purpose, studies must receive a score of at least ' 1 ' on all criteria, a single score of ' 0 ' would characterize the study as not being fitfor-purpose, consistent with the approach used in previous evaluations [34]. Our overall assessment is that there is a paucity of data that are 'fit-for-purpose' and a significant need to strengthen the acquisition of high quality data to inform the human health risk assessment of MPs in air. As additional studies report the presence of MPs in air, the ability to evaluate the relative usefulness of those studies towards strengthening a weight-ofevidence understanding of the sources, fate, transport and exposure of MPs in air can only represent a positive contribution towards a more holistic understanding regarding the environmental and human health implications that MPs represent.

\section{Conclusions}

The average TAS across studies reporting MPs in air and reviewed here is 10.7 out of a maximum total score of 22 or $48.6 \%$, implying that there remains a need for future studies to consider strengthening implementation and reporting of QA/QC protocol. Due to the absence of data reporting the contribution of MPs associated with PM10 and PM2.5, it is not possible to reliably estimate human inhalation exposure to the respirable fraction of MPs, which represents an important data need.

In helping to move our overall understanding regarding the characterization and quantification of MPs present in air there is a need to develop and agree on the application of standard sampling and analytical methods. Currently there exists several standard methods for measuring atmospheric particulates, however, the reliability of these methods for application to assessing MPs in air requires validation. Priority should be directed towards developing standard protocols of existing methods for application towards MPs, with particular attention towards the implementation of controls for reducing potential contamination during sample 
handling and transport. The development and application of high-throughput or online methods would represent important innovative and technological advances that would likely greatly facilitate improved understanding of processes and sources influencing the concentrations of MPs in air.

In helping to inform human and environmental risk assessment and align with air quality research needs, methods aimed at improved characterization and quantification of MPs $<10 \mu \mathrm{m}$, and particularly those $<2 \mu \mathrm{m}$, would be very beneficial. It is notable, however, that there are significant analytical challenges that accompany the need for monitoring particles $<10 \mu \mathrm{m}$, but that some recent developments coupling size-selective sampling and GC/MS methods may prove beneficial in deriving size-resolved mass based estimates of the distributions of MPs in air. Improved understanding of the particle size distribution of MPs in air is generally identified as a key component towards strengthening understanding of their atmospheric fate and transport, and implications towards human health and environmental risks.

\section{Abbreviations \\ CEN: European Committee for Standardization; D: Aerodynamic diameter; FPA: Focal plane array; FTIR: Fourier transform infrared; GCMS: Gas chromatography / mass spectrometry; HQI: Hit quality index; IUPAC: International Union of Pure and Applied Chemistry; LOD: Limit of detection; LOQ: Limit of quantification; MDL: Method detection limit; MPs: Microplastic particles; PA: Polyamide; PAN: Polyacrylonitrile; PC: Polycarbonate; PE: Polyethylene; PES: Polyethersulfone; PET: Polyethylene terephthalate; PM: Particulate matter; PM10: Particulate matter with aerodynamic diameter $\leq 10 \mu \mathrm{m} ; \mathrm{PM} 2.5$ : Particulate matter with aerodynamic dimeter $\leq 2.5 \mu \mathrm{m}$; PP: Polypropylene; QA/QC: Quality Assurance / Quality Control; SEM/EDX: Scanning electron microscopy / Energy dispersing X-ray; TAS: Total Assessment Score; TEOM: Tapered element oscillating microbalance; TRW: Tire road wear; WPO: Wet peroxide oxidation}

\section{Supplementary Information}

The online version contains supplementary material available at https:/doi. org/10.1186/s43591-021-00006-y.

\section{Additional file 1}

\section{Acknowledgements}

The authors acknowledge feedback and comments from colleagues at the World Health Organization on early versions of the manuscript, specifically from Jennifer De France and Pierpaolo Mudu.

\section{Disclaimer}

The authors alone are responsible for the views expressed in this publication and they do not necessarily represent the views, decisions or policies of the World Health Organization and the Medical Research Council (MRC).

\section{Authors' contributions}

The conception and design of the research supported by LS, TG and AAK, the acquisition and interpretation of the data supported by SLW, TG, and AAK with all authors having provided substantial input to drafting and editing of the manuscript. The author(s) read and approved the final manuscript.

\section{Funding}

TG acknowledges funding support from the World Health Organization and the International Council of Chemical Associations; SW acknowledges funding supported by the MRC (MR/R026521/1).

\section{Availability of data and materials}

All data generated and analysed as part of this study are included in this published article and in supplementary information.

\section{Declaration}

\section{Competing interests}

The authors declare that they have no competing interests.

\section{Author details}

${ }^{1}$ Environmental Research Group, School of Public Health, Imperial College, Michael Uren Biomedical Engineering Building, Wood Lane, White City Campus, London W12 0BZ, UK. ${ }^{2}$ TG Environmental Research, Sharnbrook, Bedfordshire, UK. ${ }^{3}$ Aquatic Ecology and Water Quality Management Group, Wageningen University, P.O. Box 47, 6700 Wageningen, DD, Netherlands. ${ }^{4}$ Department of Nutrition and Food Safety, Healthier Populations Division, World Health Organization, Geneva, Switzerland.

Received: 8 December 2020 Accepted: 9 April 2021

Published online: 17 April 2021

\section{References}

1. Arthur C, Baker J, Bamford H. Proceedings of the International Research Workshop on the Occurrence, Effects and Fate of Microplastic Marine Debris.: NOAA Technical Memorandum NOS-OR\&R-30; 2009.

2. SAPEA. A scientific perspective on microplastics in nature and society. Berlin: Science Advice for Policy by European Academies; 2019.

3. Bergmann M, Mutzel S, Primpke S, Tekman MB, Trachsel J, Gerdts G. White and wonderful? Microplastics prevail in snow from the Alps to the Arctic. Sci Adv. 2019;5(8):eaax1157.

4. Dris R, Gasperi J, Mirande C, Mandin C, Guerrouache M, Langlois V, et al. A first overview of textile fibers, including microplastics, in indoor and outdoor environments. Environ Pollut. 2017;221:453-8. https://doi.org/10.1 016/j.envpol.2016.12.013.

5. Dris R, Gasperi J, Saad M, Mirande C, Tassin B. Synthetic fibers in atmospheric fallout: a source of microplastics in the environment? Mar Pollut Bull. 2016;104(1-2):290-3. https://doi.org/10.1016/j.marpolbul.2016.01. 006.

6. Enyoh CE, Verla AW, Verla EN, Ibe FC, Amaobi CE. Airborne microplastics: a review study on method for analysis, occurrence, movement and risks. Environ Monit Assess. 2019;191(11):668. https://doi.org/10.1007/s10661-0197842-0.

7. Lassen C, Hansen SF, Magnusson K, Noren F, Hartmann N, Jensen PR, et al. Microplastics: Occurrence, effects and sources of release to the environment in Denmark. Copenhagen: The Danish Environmental Protection Agency; 2015. Contract No.: Environmental project No. 1793; 2015.

8. Magnusson K, Eliasson K, Fråne A, Haikonen K, Hultén J, Olshammar M, et al. Swedish sources and pathways for microplastics to theMarine environment. Stockholm: IVL Swedish Research Institute; 2016.

9. Panko J, Hitchcock K, Fuller G, Green D. Evaluation of tire wear contribution to PM2.5 in urban environments. Atmosphere. 2019;10(2). https://doi.org/1 $0.3390 /$ atmos 10020099 .

10. van Raamsdonk LWD, van der Zande M, Koelmans AA, Hoogenboom $R$, Peters RJB, Groot MJ, et al. Current insights into monitoring, bioaccumulation, and potential health effects of microplastics present in the food Chain. Foods. 2020;9(1). https://doi.org/10.3390/foods9010072.

11. WHO. Microplastics in drinking-water. Geneva: World Health Organization; 2019.

12. Gouin $T$, Cunliffe D, De France J, Fawell J, Jarvis P, Koelmans AA, et al. Clarifying the absence of evidence regarding human health risks to microplastic particles in drinking-water: high quality robust data wanted. Environ Int. 2020;150:106141.

13. Woodall LC, Sanchez-Vidal A, Canals M, Paterson GL, Coppock R, Sleight V, et al. The deep sea is a major sink for microplastic debris. R Soc Open Sci. 2014;1(4):140317. https://doi.org/10.1098/rsos.140317. 
14. Bank MS, Hansson SV. The plastic cycle: a novel and holistic paradigm for the anthropocene. Environ Sci Technol. 2019;53(13):7177-9. https://doi.org/1 0.1021/acs.est.9b02942

15. Cai L, Wang J, Peng J, Tan Z, Zhan Z, Tan X, et al. Characteristic of microplastics in the atmospheric fallout from Dongguan city, China: preliminary research and first evidence. Environ Sci Pollut Res Int. 2017; 24(32):24928-35. https://doi.org/10.1007/s11356-017-0116-x.

16. Dris R, Gasperi J, Rocher V, Saad M, Renault N, Tassin B. Microplastic contamination in an urban area: a case study in Greater Paris. Environ Chem. 2015;12(5):592-9.

17. Prata JC. Airborne microplastics: consequences to human health? Environ Pollut. 2018;234:115-26. https://doi.org/10.1016/j.envpol.2017.11.043.

18. Tunahan Kaya A, Yurtsever M, Çiftçi BS. Ubiquitous exposure to microfiber pollution in the air. Eur Phys J Plus. 2018;133(11). https://doi.org/10.1140/ epjp/i2018-12372-7.

19. Wright SL, Kelly FJ. Plastic and human health: a micro issue? Environ Sci Technol. 2017;51(12):6634-47. https://doi.org/10.1021/acs.est.7b00423.

20. Allen $S$, Allen $D$, Phoenix VR, Le Roux G, Durántez Jiménez $P$, Simonneau A, et al. Atmospheric transport and deposition of microplastics in a remote mountain catchment. Nat Geosci. 2019;12(5):339-44. https://doi.org/10.103 8/s41561-019-0335-5.

21. Brahney J, Hallerud M, Heim E, Hahnenberger M, Sukumaran S. Plastic rain in protected areas of the United States. Science. 2020;368(6496):1257-60. https://doi.org/10.1126/science.aaz5819.

22. Klein M, Fischer EK. Microplastic abundance in atmospheric deposition within the metropolitan area of Hamburg, Germany. Sci Total Environ. 2019; 685:96-103. https://doi.org/10.1016/j.scitotenv.2019.05.405.

23. Peeken I, Primpke S, Beyer B, Gütermann J, Katlein C, Krumpen T, et al. Arctic Sea ice is an important temporal sink and means of transport for microplastic. Nat Commun. 2018;9(1):1505. https://doi.org/10.1038/s41467018-03825-5.

24. Zhang J, Wang L, Kannan K. Microplastics in house dust from 12 countries and associated human exposure. Environ Int. 2020;134:105314. https://doi. org/10.1016/.jenvint.2019.105314.

25. US EPA. Integrated science assessment for particulate matter. Research Triangle Park: US Environmental Protection Agency, Center for Public Health and Environmental Assessment, Office of Research and Development; 2019.

26. WHO. Air quality guidelines : global update 2005 : particulate matter, ozone, nitrogen dioxide, and sulfur dioxide, vol. ix. Copenhagen: World Health Organization; 2006. p. 484. ill. (chiefly col.) p

27. ACGIH. 2005 TLVs and BEls: based on the documentation of the threshold limit values for chemical substances and physical agents and biological exposure indices. Cincinnati: American Conference of Governmental Industrial Hygienists; 2005.

28. CEN. Workplace Atmospheres - Size fraction definitions for measurement of airborne particles. Brussels: European Standard EN 481, European Standardization Committee (CEN); 1993.

29. Brown JS, Gordon T, Price O, Asgharian B. Thoracic and respirable particle definitions for human health risk assessment. Part Fibre Toxicol. 2013;10(1): 12. https://doi.org/10.1186/1743-8977-10-12.

30. Bennett WD, Zeman KL. Effect of race on fine particle deposition for oral and nasal breathing. Inhal Toxicol. 2005;17(12):641-8. https://doi.org/10.1 080/08958370500188984

31. Bennett WD, Zeman KL, Jarabek AM. Nasal contribution to breathing with exercise: effect of race and gender. J Appl Physiol (1985). 2003;95(2):497503.

32. Bennett WD, Zeman KL, Jarabek AM. Nasal contribution to breathing and fine particle deposition in children versus adults. J Toxicol Environ Health Part A. 2008;71(3):227-37. https://doi.org/10.1080/15287390701598200.

33. Londahl J, Moller W, Pagels JH, Kreyling WG, Swietlicki E, Schmid O. Measurement techniques for respiratory tract deposition of airborne nanoparticles: a critical review. J Aerosol Med Pulm Drug Deliv. 2014;27(4): 229-54. https://doi.org/10.1089/jamp.2013.1044.

34. Koelmans AA, Mohamed Nor NH, Hermsen E, Kooi M, Mintenig SM, De France J. Microplastics in freshwaters and drinking water: critical review and assessment of data quality. Water Res. 2019;155:410-22. https://doi.org/10.1 016/j.watres.2019.02.054.

35. Catarino Al, Macchia V, Sanderson WG, Thompson RC, Henry TB. Low levels of microplastics (MP) in wild mussels indicate that MP ingestion by humans is minimal compared to exposure via household fibres fallout during a meal. Environ Pollut. 2018;237:675-84. https://doi.org/10.1016/j.envpol.2018.02.069.
36. Hermsen E, Mintenig SM, Besseling E, Koelmans AA. Quality criteria for the analysis of microplastic in biota samples: a critical review. Environ Sci Technol. 2018;52(18):10230-40. https://doi.org/10.1021/acs.est.8b01611.

37. de Ruijter VN, Redondo-Hasselerharm PE, Gouin T, Koelmans AA. Quality criteria for microplastic effect studies in the context of risk assessment: a critical review. Environ Sci Technol. 2020;54(19):11692-705. https://doi.org/1 0.1021/acs.est.0c03057.

38. Koelmans, AA, Diepens NJ, Mohamed Nor NH. Weight of evidence for the microplastic vector effect in the context of chemical risk assessment. In: Bank MS, editor. Plastic in the Environment: Pattern and Process. Springer Open. in press.

39. Brander SM, Renick VC, Foley MM, Steele C, Woo M, Lusher A, et al. EXPRESS: sampling and QA/QC: a guide for scientists investigating the occurrence of microplastics across matrices. Appl Spectrosc. 2020;74:3702820945713.

40. Cowger W, Booth AM, Hamilton BM, Thaysen C, Primpke S, Munno K, et al. Reporting guidelines to increase the reproducibility and comparability of research on microplastics. Appl Spectrosc. 2020;74:3702820930292.

41. Cowger W, Gray A, Christiansen SH, De Frond H, Deshpande A, Hermabessiere L, et al. EXPRESS: critical review of processing and classification techniques for images and spectra in microplastic research. Appl Spectrosc. 2020;74:3702820929064.

42. Wright SL, Ulke J, Font A, Chan KLA, Kelly FJ. Atmospheric microplastic deposition in an urban environment and an evaluation of transport. Environ Int. 2020;136:105411. https://doi.org/10.1016/j.envint.2019.105411.

43. Gaston E, Woo M, Steele C, Sukumaran S, Anderson S. EXPRESS: microplastics differ between indoor and outdoor air masses: insights from multiple microscopy methodologies. Appl Spectrosc. 2020;74: 3702820920652

44. Wang X, Li C, Liu K, Zhu L, Song Z, Li D. Atmospheric microplastic over the South China Sea and East Indian Ocean: abundance, distribution and source. J Hazard Mater. 2020;389:121846. https://doi.org/10.1016/j.jhazmat.2 019.121846.

45. Vianello A, Jensen RL, Liu L, Vollertsen J. Simulating human exposure to indoor airborne microplastics using a breathing thermal manikin. Sci Rep. 2019;9(1):8670. https://doi.org/10.1038/s41598-019-45054-w.

46. Liu K, Wang X, Wei N, Song Z, Li D. Accurate quantification and transport estimation of suspended atmospheric microplastics in megacities: implications for human health. Environ Int. 2019;132:105127. https://doi. org/10.1016/j.envint.2019.105127.

47. Stanton T, Johnson M, Nathanail P, MacNaughtan W, Gomes RL. Freshwater and airborne textile fibre populations are dominated by 'natural', not microplastic, fibres. Sci Total Environ. 2019;666:377-89. https://doi.org/10.101 6/j.scitotenv.2019.02.278.

48. Liu K, Wang X, Fang T, Xu P, Zhu L, Li D. Source and potential risk assessment of suspended atmospheric microplastics in Shanghai. Sci Total Environ. 2019;675:462-71. https://doi.org/10.1016/j.scitotenv.2019.04.110.

49. Roblin B, Aherne J. Moss as a biomonitor for the atmospheric deposition of anthropogenic microfibres. Sci Total Environ. 2020;715:136973. https://doi. org/10.1016/j.scitotenv.2020.136973.

50. Li Y, Shao L, Wang W, Zhang M, Feng X, Li W, et al. Airborne fiber particles: types, size and concentration observed in Beijing. Sci Total Environ. 2020; 705:135967. https://doi.org/10.1016/j.scitotenv.2019.135967.

51. Su L, Nan B, Craig NJ, Pettigrove V. Temporal and spatial variations of microplastics in roadside dust from rural and urban Victoria, Australia: implications for diffuse pollution. Chemosphere. 2020;252:126567. https:// doi.org/10.1016/j.chemosphere.2020.126567.

52. Peller JR, Eberhardt L, Clark R, Nelson C, Kostelnik E, Iceman C. Tracking the distribution of microfiber pollution in a southern Lake Michigan watershed through the analysis of water, sediment and air. Environ Sci Process Impacts. 2019;21(9):1549-59. https://doi.org/10.1039/C9EM00193J.

53. Dehghani S, Moore F, Akhbarizadeh R. Microplastic pollution in deposited urban dust, Tehran metropolis, Iran. Environ Sci Pollut Res Int. 2017;24(25): 20360-71. https://doi.org/10.1007/s11356-017-9674-1.

54. Abbasi S, Keshavarzi B, Moore F, Turner A, Kelly FJ, Dominguez AO, et al. Distribution and potential health impacts of microplastics and microrubbers in air and street dusts from Asaluyeh County, Iran. Environ Pollut. 2019;244: 153-64. https://doi.org/10.1016/j.envpol.2018.10.039.

55. Liu C, Li J, Zhang Y, Wang L, Deng J, Gao Y, et al. Widespread distribution of PET and PC microplastics in dust in urban China and their estimated human exposure. Environ Int. 2019;128:116-24. https://doi.org/10.1016/.envint.2019. 04.024. 
56. Yukioka S, Tanaka S, Nabetani Y, Suzuki Y, Ushijima T, Fujii S, et al. Occurrence and characteristics of microplastics in surface road dust in Kusatsu (Japan), Da Nang (Vietnam), and Kathmandu (Nepal). Environ Pollut. 2020:256:113447. https://doi.org/10.1016/j.envpol.2019.113447.

57. Syafei AD, Nurasrin NR, Assomadi AF, Boedisantoso R. Microplastic pollution in the ambient air of Surabaya, Indonesia. Curr World Environ. 2019;14(2): 290-8. https://doi.org/10.12944/CWE.14.2.13.

58. Asrin NRN, Dipareza A. Microplastics in ambient air (case study: Urip Sumoharjo street and Mayjend Sungkono street of Surabaya City, Indonesia). IAETSD - J Adv Res Appl Sci. 2019;6(1):54-7.

59. Currie LA. Detection and quantification limits: origins and historical overview. Anal Chim Acta. 1999;391(2):127-34. https://doi.org/10.1016/ S0003-2670(99)00105-1.

60. Long GL, Winefordner JD. Limit of detection a closer look at the IUPAC definition. Anal Chem. 1983:55(7):712A-24A.

61. Prata JC, Alves JR, da Costa JP, Duarte AC, Rocha-Santos T. Major factors influencing the quantification of Nile Red stained microplastics and improved automatic quantification (MP-VAT 2.0). Sci Total Environ. 2020;719: 137498.

62. Isobe A, Buenaventura NT, Chastain S, Chavanich S, Cózar A, DeLorenzo M, et al. An interlaboratory comparison exercise for the determination of microplastics in standard sample bottles. Mar Pollut Bull. 2019;146:831-7. https://doi.org/10.1016/j.marpolbul.2019.07.033.

63. Pfeiffer F, Fischer EK. Various digestion protocols within microplastic sample processing —evaluating the resistance of different synthetic polymers and the efficiency of biogenic organic matter destruction. Front Environ Sci. 2020;8. https://doi.org/10.3389/fenvs.2020.572424.

64. Wright SL, Levermore JM, Kelly FJ. Raman spectral imaging for the detection of inhalable microplastics in ambient particulate matter samples. Environ Sci Technol. 2019;53(15):8947-56. https://doi.org/10.1021/acs.est.8b06663.

65. Mintenig SM, Kooi M, Erich MW, Primpke S, Redondo-Hasselerharm PE, Dekker SC, et al. A systems approach to understand microplastic occurrence and variability in Dutch riverine surface waters. Water Res. 2020;176:115723. https://doi.org/10.1016/j.watres.2020.115723.

66. Zhang Y, Gao T, Kang S, Sillanpää M. Importance of atmospheric transport for microplastics deposited in remote areas. Environ Pollut. 2019;254(Pt A): 112953.

67. Amato-Lourenço LF, Dos Santos GL, de Weger LA, Hiemstra PS, Vijver MG, Mauad T. An emerging class of air pollutants: potential effects of microplastics to respiratory human health? Sci Total Environ. 2020;749: 141676. https://doi.org/10.1016/j.scitotenv.2020.141676.

68. Chen G, Feng Q, Wang J. Mini-review of microplastics in the atmosphere and their risks to humans. Sci Total Environ. 2020;703:135504. https://doi. org/10.1016/j.scitotenv.2019.135504.

69. Qiu R, Song Y, Zhang X, Xie B, He D. Microplastics in urban environments: sources, pathways, and distribution. In: He D, Luo Y, editors. Microplastics in terrestrial environments: emerging contaminants and major challenges. Cham: Springer International Publishing; 2020. p. 41-61. https://doi.org/10.1 007/698_2020_447.

70. Andersson-Sköld Y, Johannesson M, Gustafsson M, Järlskog I, Lithner $D$, Polukarova $\mathrm{M}$, et al. Microplastics from tyre and road wear: a literature review 2020

71. Fischer M, Scholz-Böttcher BM. Microplastics analysis in environmental samples - recent pyrolysis-gas chromatography-mass spectrometry method improvements to increase the reliability of mass-related data. Anal Methods. 2019;11(18):2489-97. https://doi.org/10.1039/C9AY00600A.

72. Ball H, Cross R, Grove E, Horton A, Johnson A, Jürgens M, et al. Sink to river - river to tap: A review of potential risks from nanoparticles and microplastics. London: UK Water Industry Research; 2019. Report No.: Report Ref. No. 19/EQ/01/18

73. Owen MK, Ensor DS, Sparks LE. Airborne particle sizes and sources found in indoor air. Atmos Environ Part A. 1992;26(12):2149-62. https://doi.org/10.101 6/0960-1686(92)90403-8.

74. Koelmans AA, Redondo-Hasselerharm PE, Mohamed Nor NH, Kooi M. Solving the nonalignment of methods and approaches used in microplastic research to consistently characterize risk. Environ Sci Technol. 2020;54(19): 12307-15. https://doi.org/10.1021/acs.est.0c02982.

\section{Publisher's Note}

Springer Nature remains neutral with regard to jurisdictional claims in published maps and institutional affiliations.

\section{Submit your manuscript to a SpringerOpen ${ }^{\circ}$ journal and benefit from:}

- Convenient online submission

- Rigorous peer review

- Open access: articles freely available online

- High visibility within the field

- Retaining the copyright to your article

Submit your next manuscript at $\boldsymbol{\nabla}$ springeropen.com 